\title{
Intelligence, Race, and Genetics
}

\author{
Robert J. Sternberg, Elena L. Grigorenko, and Kenneth K. Kidd
}

Yale University

In this article, the authors argue that the overwhelming portion of the literature on intelligence, race, and genetics is based on folk taxonomies rather than scientific analysis. They suggest that because theorists of intelligence disagree as to what it is, any consideration of its relationships to other constructs must be tentative at best. They further argue that race is a social construction with no scientific definition. Thus, studies of the relationship between race and other constructs may serve social ends but cannot serve scientific ends. No gene has yet been conclusively linked to intelligence, so attempts to provide a compelling genetic link of race to intelligence are not feasible at this time. The authors also show that heritability, a behaviorgenetic concept, is inadequate in regard to providing such a link.

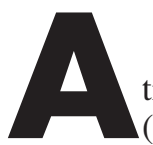

number of scholars claim to have studied relationships among intelligence, race, and genetics (e.g., Herrnstein \& Murray, 1994; Rushton, 1995). The thesis of this article is that these studies are not grounded in scientifically derived constructs but rather in folk beliefs about them. There is a big difference between studying relationships between constructs and folk beliefs regarding such relationships. The bigger problem, however, is when one studies the latter but believes one is studying the former.

In this article, we first review the nature of intelligence. We then discuss the relationship between intelligence and race. Finally, we reflect upon the relationships among intelligence, race, and genetics.

\section{Intelligence}

To study the interrelationships among intelligence, race, and genetics, we need to know what intelligence is. We do not know. Hence, any conclusions about its relationships to other constructs will be, at best, tentative.

\section{Formal Theories of Intelligence}

One way to figure out what intelligence is has been to ask experts. Two major symposia have done so ("Intelligence and Its Measurement," 1921; Sternberg \& Detterman, 1986). Each of the roughly two dozen definitions produced in each symposium was different. There were some common threads, such as the importance of adaptation to the environment and of the ability to learn, but these constructs themselves are not well specified. Moreover, very few tests of intelligence directly measure either one. Tests do not offer adaptive tasks one is likely to face in everyday life.
Nor do any tests, except dynamic tests (see Sternberg \& Grigorenko, 2002a) that require learning at the time of the test, directly measure ability to learn. Rather, traditional tests focus much more on measuring past learning, which can be the result of differences in many factors, including motivation and available opportunities to learn.

Some theories of intelligence extend this definition by suggesting that there is a general factor of intelligence, often labeled $g$, that underlies all adaptive behavior (Brand, 1996; Jensen, 1998; see essays in Sternberg \& Grigorenko, 2002b). In many theories, including the theories most widely accepted today (e.g., Carroll, 1993; Gustafsson, 1994; Horn, 1994), other mental abilities are hierarchically nested under this general factor at successively greater levels of specificity. For example, Carroll has suggested that three levels can nicely capture the hierarchy of abilities, whereas Cattell (1971) and Vernon (1971) suggested two levels that were especially important. In the case of Cattell, nested under general ability are fluid abilities of the kind needed to solve abstract reasoning problems such as figural matrices or series completions and crystallized abilities of the kind needed to solve problems of vocabulary and general information. In the case of Vernon, the two levels corresponded to verbal-educational and practicalmechanical abilities. What we know about group differences largely involves so-called $g$ and major group factors, such as verbal and spatial skills. More modern theories extend intelligence much further, for example, to creative and practical as well as analytical abilities (Sternberg,

Robert J. Sternberg, PACE Center, Yale University; Elena L. Grigorenko, PACE Center and Child Study Center, Yale University; Kenneth K. Kidd, Department of Genetics, Yale University.

Preparation of this article was supported by National Science Foundation Grant REC-9979843; by a government grant under the Javits Act Program (Grant R206R000001), as administered by the Institute of Educational Sciences, U.S. Department of Education; by U.S. Department of Education, Institute for Educational Sciences Award 31-1992-701, as administered by the Temple University Laboratory for Student Success; and by National Institutes of Health Grants AA09379 and GM57672 and National Science Foundation Grant BCS0096588. Grantees undertaking such projects are encouraged to freely express their professional judgment. This article, therefore, does not necessarily represent the positions or policies of the U.S. government, and no official endorsement should be inferred.

We are grateful to Julian Elliott, Jeremy Gray, Linda Jarvin, Jennifer Jordan, Scott Kaufman, Richard Nisbett, David Preiss, Steven Stemler, and Karin Weis for comments that helped improve this article.

Correspondence concerning this article should be addressed to Robert J. Sternberg, PACE Center, Yale University, Box 208358, New Haven, CT 06520-8358. E-mail: robert.sternberg@yale.edu 


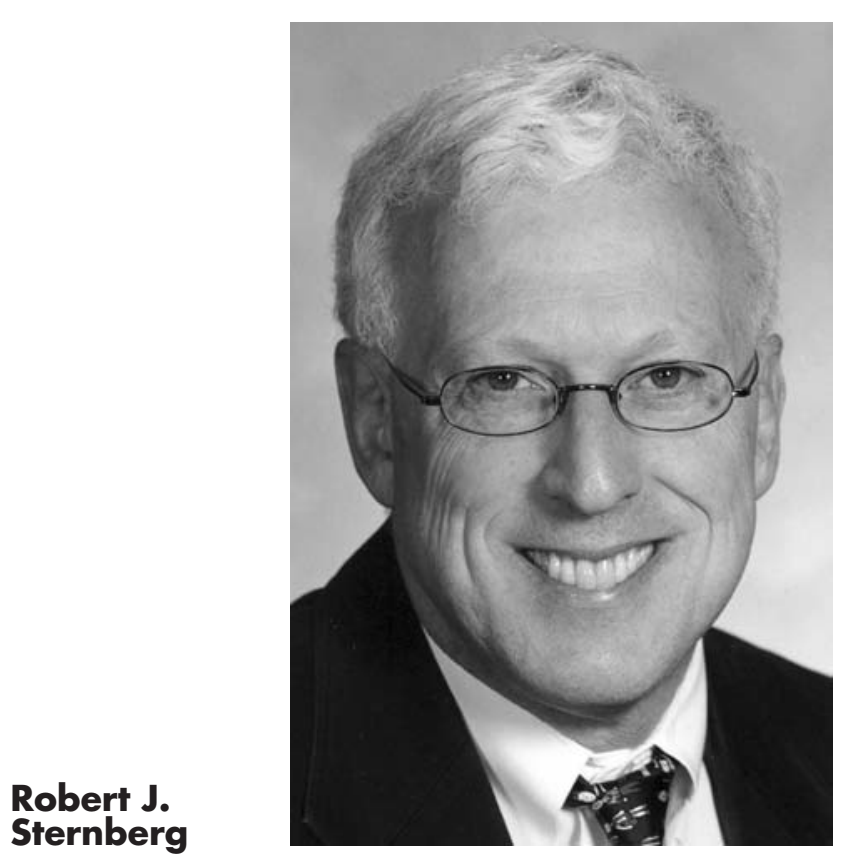

1997; Sternberg et al., 2000) or to eight distinct multiple intelligences (Gardner, 1999a, 1999b).

\section{Informal Theories of Intelligence}

Lay conceptions of intelligence are quite a bit broader than conceptions of psychologists who believe in $g$ (Berry, 1974; Sternberg \& Kaufman, 1998). For example, in a study of people's conceptions of intelligence (Sternberg, Conway, Ketron, \& Bernstein, 1981; see also Sternberg, 1985), Sternberg and his colleagues found that laypersons had a three-factor view of intelligence as comprising verbal, practical problem-solving, and social competence abilities. Only the first of these abilities is measured by conventional tests. Experts in different occupations in the United States have somewhat different conceptions of intelligence, with their views of the relevant attributes tending to match the requirements of their occupations (Sternberg, 1985). And conceptions of intelligence around the world vary even more than they do in the United States (Grigorenko et al., 2001; Sternberg, 2004b; Yang \& Sternberg, 1997a, 1997b).

The way intelligence is usually defined in studies of the alleged relationships among intelligence, race, and genetics is in terms of Boring's (1923) operational definition of intelligence as whatever it is that IQ tests measure. This definition is unsatisfactory for at least three different reasons. First, it is circular, defining the construct in terms of the operation and the operation in terms of the construct. Second, so-called IQ tests do not all measure the same thing (Mackintosh, 1998). Third, as indicated, theorists of intelligence do not themselves agree as to what intelligence is.

For convenience, we can follow Boring and operationally define intelligence in terms of IQ as measured by conventional tests. But it is not clear that tests of IQ measure the same construct among all people to whom the tests are applied (Sternberg, 2004a, 2004b). The more culturally distinct the people, the greater the differences in what the items measure. In part, this is because IQ test items are largely measures of achievement at various levels of competency (Sternberg, 1998, 1999, 2003). Items requiring knowledge of the fundamentals of vocabulary, information, comprehension, and arithmetic problem solvingso-called measures of crystallized abilities (Cattell, 1971; Horn, 1994) — are clearly measures of achievement. Items requiring fluid abilities (Cattell, 1971; Horn, 1994) involving abstract reasoning, once thought to be culture fair (Cattell \& Cattell, 1963), have proven even more susceptible to effects of cultural and other environments than tests of crystallized abilities (Flynn, 1984, 1987; Neisser, 1998), suggesting they are in no way "culture fair." Western-style schooling even more extensively inculcates these ways of thinking than it does those measured by tests of crystallized abilities.

In summary, it is probably more accurate to refer to existing studies as assessing the relation between "IQ" or "psychometric $g$ " and what is labeled as race than as assessing "intelligence" and these other constructs. Does the language we use matter? Yes. We need to acknowledge that we are using convenient, partial operationalizations of the construct of intelligence, and nothing more. As professionals, some of us may understand that there is a large gap between the conceptualization and operationalization of intelligence. Others of us may act as though IQ tests somehow provide the kind of measurement of intelligence that a tape measure provides of height. When we are dealing with the lay audiences who learn about our work, it is especially important that we acknowledge that we have nothing even vaguely close to a "tape measure" of intelligence.

\section{Intelligence and Race \\ "Out of Africa"}

Most scientists who study such matters believe that those humans of whom we are descendants all lived in Africa (e.g., Tishkoff et al., 1996; Tishkoff \& Kidd, 2004; Walter et al., 2000). They first appeared roughly 200,000 years ago. For whatever reasons - to find food, to satisfy wanderlust, to find better protection against predators, to find more land-small numbers of unrepresentative people started to migrate out of Africa about 100,000 years ago (Stringer, 1990).

The "out-of-Africa" hypothesis places the first immigrants from Africa in southwestern Asia. Over the course of tens of thousands of years, that initial non-African population expanded until now at least some of its descendants can be found on all continents and in most regions of those continents except for Antarctica, which, in general, is too cold to be hospitable, at least for modern humans. As people migrated, they adapted so as better to fit their environments. Much of that adaptation was cultural-different clothing, different foods, for example_-but some of 


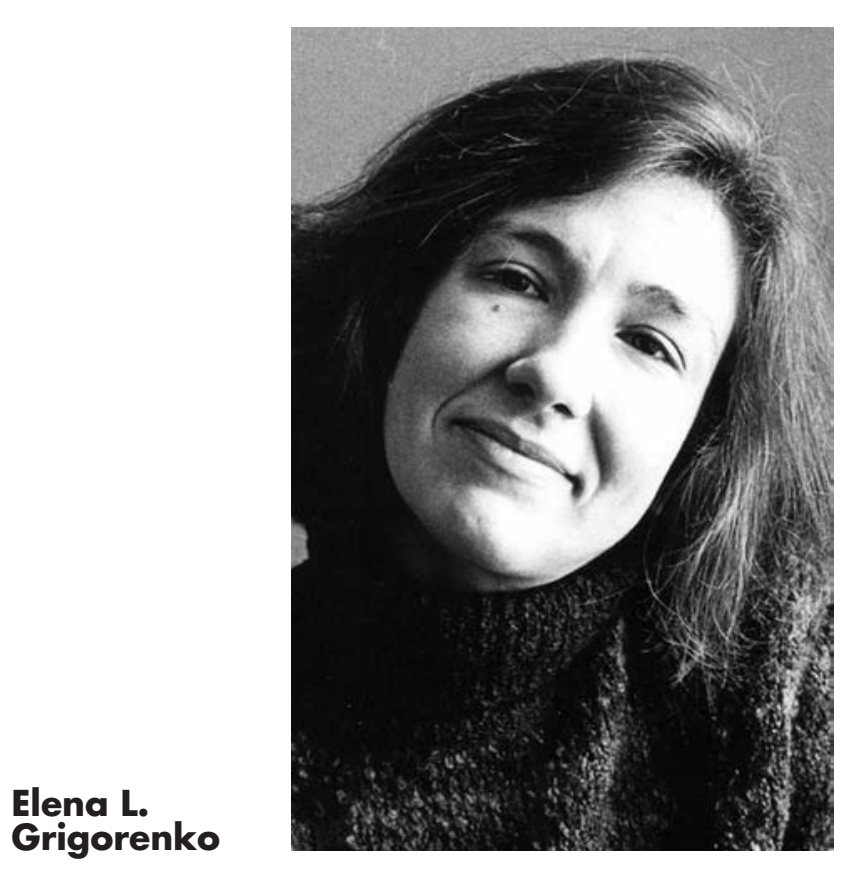

it was genetic. However, it is difficult to prove that traits seen to differ are truly the result of different selective pressures, that is, genetic adaptations. A major reason for the difficulty is that at the genetic level there are quantitative differences in frequencies of genetic variants, not qualitative genetic differences, among populations. When multiple forms of a DNA sequence, either a coding sequence or a noncoding sequence, are present, the sequence is referred to as polymorphic and the forms as alleles at the polymorphism. Among populations of various kinds, allele frequency differences at polymorphisms are the rule because of the chance effects known as random genetic drift. In other words, as a result of both natural and social events, only some genotypes are transmitted through generations; the others are lost. The lack of predictability in who will have children and who will not introduces powerful random noise into allele frequencies between generations. Thus, observing different allele frequencies does not, in and of itself, imply that local selection has operated.

\section{Mechanisms of Genetic Influence}

Four mechanisms have influenced the genetic evolution of populations (Templeton, 2002). We consider each in turn.

The first is mutation, by which genes change in random ways. Mutation results in the rise of both functional (i.e., coding) and nonfunctional (i.e., noncoding) polymorphisms.

The second is random genetic drift, by which alleles in finite populations may change in frequency over time as a result of the accumulation of random sampling error in the passing on of alleles from generation to generation. When a very small number of individuals migrate and start a new population, the sampling error (random genetic drift) is very large, and allele frequencies in the new population may be very different from those in the parent population. As the new population grows over a few generations, the magnitude of the sampling error per generation decreases, and the new population will continue to have very different frequencies from the parent population. This extreme form of random genetic drift is referred to as a "founder effect," because the population expanded from very few founders with a relatively restricted gene pool. For example, available evidence suggests that a small group of individuals left Africa and over time allele frequencies changed markedly from those in the African populations left behind.

The third mechanism is gene flow or genetic exchange, by which interbreeding among certain groups of individuals potentially results in those populations becoming increasingly similar to each other. Two populations that start off quite different genetically, if they mate, can produce offspring that represent the genes present in both of the original populations.

The fourth mechanism is natural selection, by which organisms with gene patterns that are adaptive to a given environment become more prevalent over time. For example, organisms that can adapt to changing climatic patterns are at an advantage over those that adapt only with great difficulty.

\section{Migration and Adaptation}

Although all of these mechanisms are of importance, here we illustrate only that of natural selection. Consider the following example. During the Industrial Revolution in late-19th-century England, a particular dark-colored moth became more prevalent than a related light-colored moth. Why? It is believed industrial pollution had blackened the forests and improved the darker moth's camouflage against predators such as birds. The light-colored moth was too visible to survive. More recently, however, with restrictions on air pollution, the light moth has made a comeback (Cook, 2003). The point, of course, is that natural selection is a constantly shifting process. It is influenced not only by an organism's biology, but also by the interaction of that biology with environmental conditions (Sternberg, 2004c).

Is it better from the standpoint of adaptation to the physical environment to be a black moth or a light-colored moth? It depends on the interaction between the organism's attributes, including color, and the particular environment. Is it better from the same adaptive standpoint to be a Black person or a light-colored person? The answer is the same, of course. In zones with more intense exposure to sunlight, darker skin puts individuals at an adaptive advantage. The melanin that acts as a pigmentation to produce darker skin better protects individuals against the damage that large amounts of ultraviolet radiation can cause to the skin. Left unchecked, this radiation increases susceptibility to skin cancer, especially melanoma, a form of skin cancer that easily can become fatal. In zones with weaker exposure to sunlight, lighter skin is an advantage.

One explanation of lighter coloration pertains to vitamin absorption. People rely on sunlight to produce active vitamin $\mathrm{D}_{3}$ in the capillaries. The active form does not occur in great quantities in the food most people eat. 


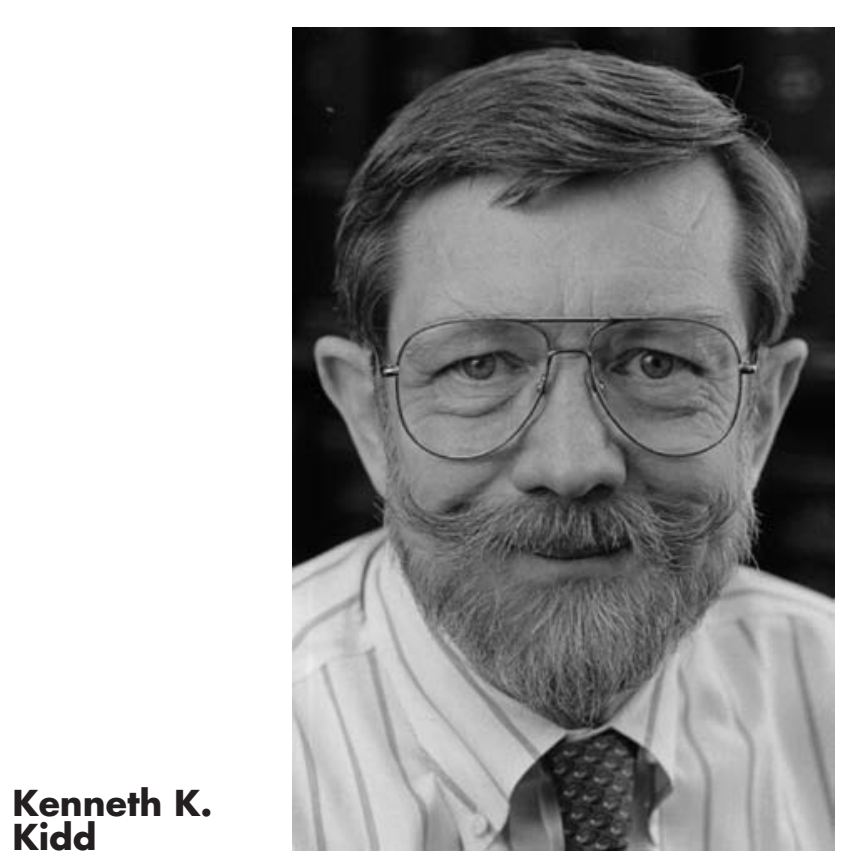

Indeed, often milk is supplemented with vitamin $\mathrm{D}_{3}$ to prevent deficiencies. Lighter skin allows greater bodily production of vitamin $\mathrm{D}_{3}$. Deficiencies in vitamin $\mathrm{D}_{3}$ can cause rickets in children and osteoporosis in adults (O'Neil, 2004).

A second explanation is of a different kind. There is as yet no conclusive evidence of positive selection for light coloration. Instead, evidence to date may indicate that light pigmentation in climates distant from the equator represents a lessening of the selective factors that lead to dark pigmentation near the equator rather than to any particular factors leading to lighter pigmentation per se (Harding et al., 2000). Individual moths or other animals do not radically change in color in the course of their lifetimes. Rather, over time, those descendants that are better adapted are more likely to survive and reproduce, and thus distributions of traits change. Human populations adapt over many generations, but not all organisms do. Some adapt very rapidly. Generations of bacteria, for example, adapt rapidly because of their extremely rapid rates of reproduction. It is for this reason that the same medication, amoxicillin, that was effective in treating ear infections in the children of 20 years ago is so much less effective in treating ear infections in the children of today. Bacteria have adapted, in the same way that malaria parasites have adapted to many quinine-based treatments and in the same way that the HIV virus is adapting to the medications being used to treat it. All biological populations adapt, whether bacterial, human, or anything else.

There is another key fact in this story. Aside from the explanations of skin color, there are not many scientifically supportable selective explanations for the differences observed in people from different parts of the world. It is probable that much of the variation seen among groups of humans indirectly resulted from the pattern of expansion and migrations accompanied by random genetic drift. Over the years, frequencies of DNA variants changed only slightly in terms of total DNA composition but changed enough to produce differences, many of which we still do not fully understand. The changes are numerous. Less than $1 \%$ of human DNA varies globally, in the 3 billion nucleotide positions in the human genome; however, that $1 \%$ creates a large number of potential differences between any two people. Some regional differences are observable, and others less so. For example, one will see larger proportions of blond hair and blue eyes in people born in European countries than in those born in Asian ones. In addition, one will see shorter people, on average, among those born in Asia than among those born in Europe, and one will see wider noses in West Africa, on average, than in East Africa. In other words, within geographic groups, there is variation, and, as it turns out, tremendous variation.

\section{Race as a Social Construction}

Where does race fit into the genetic pattern? Actually, it fits nowhere. Race is a socially constructed concept, not a biological one. It derives from people's desire to classify. People seem to be natural classifiers. Perhaps this tendency reflects, in part, what Gardner (1999a, 1999b) has referred to as "naturalistic intelligence." Or perhaps it merely reflects a need to discern order in or even to impose it on nature. Any set of observations can be categorized in multiple ways. People impose categorization and classification schemes that make sense to them and that, in some cases, favor their particular goals.

If one looks at geographic patterns, one will find many attributes that correlate with geography; nearby populations tend to be similar and distant populations dissimilar. This pattern is similar to common ideas of socially defined races but is more complex (K. K. Kidd, Pakstis, Speed, \& Kidd, 2004; Rosenberg et al., 2002; Tishkoff \& Kidd, 2004). People in different places come to demonstrate different characteristics by adaptations to different environments, such as heterozygosity for sickle-cell hemoglobin as a partial protection against malaria, as well as by accumulation of random genetic drift. But as is so often the case, the same trait that may be adaptive in one circumstance may be maladaptive in another. For example, there is no advantage of sickle-cell hemoglobin in the absence of malaria, and the anemia that results in homozygotic individuals poses a serious disadvantage.

Other adaptations are equally fickle. Today, our population is paying the price of tens of thousands of years in which people became genetically programmed to enjoy fats and sugars and to eat as much of them as they could when they had the opportunity. In the contemporary environment, the result is high levels of overweight and obesity. Some people have more of a genetic predisposition to gain weight than others. Social stratification-classifying people into categories of higher and lower status in a societyhas already ensued on the basis of weight (Brownell \& Horgen, 2003). Whether, ultimately, people with a genetic predisposition toward fatness will be classified as being of 
a separate race remains to be seen. The point is that an adaptation that is positive at one time or place may be indifferent at another and negative at still another.

One could pick any of a number of traits correlated with geographic patterns and find correlations with other related traits. It would be foolhardy, however, to view any one of these traits as causative of the others. That is what people have done who have viewed differences in so-called races as somehow causative of differences in IQ. It also would be foolhardy to group fairly arbitrary sets of traits and constructs that one then reifies as being natural, somehow God-given categories. One will find a distribution of traits in any of these groups, with only slightly more differentiation in comparisons involving individuals from different groups than in comparisons involving individuals from the same group (K. K. Kidd et al., 2004). Why would people do this, then? One reason is to justify existing social stratifications or to create new ones.

We could of course refer to moths as being of different "races" (black and white) in the same way we sometimes refer to humans as being of different "races." We do not typically use the term for moths, presumably because we are less interested in creating social stratifications for moths than for people, and race is one way to help create these stratifications. Of course, we recognize that our article may have the opposite effect from that intended: Some believers in biological race may realize that moths (and perhaps dogs, cats, and other animals that come in multiple colors) have been sorely neglected in the literature on racial differences and that there is still time to remedy this situation. To the extent we define race as simply different sets of physical features, we could say, of course, that the moths are of different races. But the term, used in this way, becomes simply a word for saying the moths look different! And the surplus meaning associated with the word, at least as it is used in human descriptions, vanishes.

Over time, peoples who migrated changed both by chance and by adaptation to their environments in various ways. What is "good" depends on the adaptations that need to be made, and these adaptations change from time to time and place to place. For example, our ancestors in Africa were almost certainly dark-skinned because dark skin provided better protection against the particular challenges of the environment, most notably ultraviolet and other harmful forms of radiation. Other traits, such as straight or curly hair, have no evident adaptive value, and population differences probably reflect chance differences. Curiously, then, socially constructed judgments as to how socially to stratify people are made on bases that have no relation to the original reasons people came to look one way or another.

There is nothing special about skin color that serves as a basis for differentiating humans into so-called races. Any two groups of people that differ in one way are likely to differ in a cluster of ways. For example, as noted by Marks (2002), geneticists have found that $54 \%$ of people who have designated themselves as Hebrew priests, many of whom have the surname of Cohen, have a certain pattern of two genes on the Y chromosome. In contrast, only $33 \%$ of
Jews who do not view themselves as priests exhibit this pattern. What conclusion is to be drawn? Well, the correct conclusion is that different groups of people will differ in various respects. The authors of the study concluded that one could infer a genetic Jewish priestly line dating back to the biblical Aaron (Skorecki et al., 1997). Other bases for differentiation could be chosen as well, including the aforementioned one of girth.

As another example, Fish (2002) has pointed out that people who have lived over many generations in cold climates, such as Eskimos, have tended to develop rounded bodies to maintain heat and thus stay warmer. Some populations in very hot climates, such as the Masai, have tended instead to develop lanky bodies. The hypothesis is that the high ratio of surface area to volume results in their radiating a high amount of heat and thus staying cooler. Although reasonable, both adaptation hypotheses lack rigorous scientific proof. Possibly, they could be just coincidences. Scientists do not know for sure.

In the American folk taxonomy of race, as argued by Fish (2002), lanky and rounded people can represent, respectively, two kinds of Blacks and Whites. But one could as easily decide that a more "basic" taxonomy of races would be in terms of lanky and rounded bodies, in which case there would be Black and White members of the lanky and rounded races. One would find a number of genetic patterns that, on average, correspond to lankiness and roundedness, in the same way one would find genetic correlate patterns corresponding to darker versus lighter skin, Cohens versus non-Cohens, or basketball players versus wrestlers.

It has been argued that the challenges faced by those who migrated to northern climates were greater than those faced by people in southern climates and that this difference might have led to higher intelligence levels among those who went northward (see Rushton, 1995). However, anyone who has spent any significant time in Africa might well dispute this claim. One of the greatest challenges of tropical climates is fighting tropical diseases to survive, and the challenges of fighting diseases are greater in the tropics than they are further north. Indeed, children acquire from an early age specialized knowledge, not acquired further north, regarding natural herbal medicines that can be used to combat tropical illnesses (Sternberg et al., 2001). To the extent that warmer climates encourage greater aggression (see, e.g., Nisbett \& Cohen, 1996), learning how to compete successfully so as to survive in such environments also might promote intellectual development. We are not arguing that people in warmer climates did indeed develop higher intelligence but, rather, that one could create speculative arguments supporting greater intellectual growth in such climates, as has been done to support the notion that there was greater intellectual growth as a result of challenges up north. Indeed, post hoc evolutionary arguments made in the absence of fossils at times can have the character of ad hoc "just so" stories designed to support, in retrospect, whatever point the author wishes to make about present-day people. 
Differences in socially constructed races stem largely from geographic dispersions that began about 100,000 years ago and continued until about 3,000 years ago in some areas. Today we see the physical correlates left by these dispersions. Much of that variation is continuous across distances, but with different traits showing different rates and patterns of change. What "race" does is to reify these differences as deriving from some imagined natural grouping of people that does not in fact exist, except in our heads.

What we see in terms of skin color correlates very well with our developed folk taxonomies but only weakly with genetic differentiations. For example, the amount of genetic variation in Africa is enormous and is much greater than that in the rest of the world (e.g., Tishkoff \& Kidd, 2004; Tishkoff \& Williams, 2002). In contrast, in terms of the amount of phenotypic variation, or differences in appearance, Africa is at least comparable to the rest of the world. The phenotypic differences are nevertheless notable. For example, in Africa, one can find very tall Masai and very short Pygmies who probably gained an adaptive advantage by virtue of their shortness for locomotion through forest vegetation (Fish, 2002). Yet, some may lump together all of these Africans as the same, despite the fact that genetically they differ more from each other, in many cases, than they do from those who perceive themselves to be of higher social, or even biological, value.

Humans have devised various metaphors for understanding why some people are more successful, according to whatever standards society invents, than others. Usually, comparisons are drawn by those who consider themselves successful for the benefit of others who consider themselves successful or on the road to success (e.g., see Herrnstein \& Murray's, 1994, discussion of meritocracy). A curiosity of history is that people come to believe in the reality of their own metaphors. For example, some have believed, and some still believe, in "royal blood." Educated people probably realize that the expression is metaphorical; others probably believe that the blood of royals differs in some key respect from the blood of others.

For readers of this journal, a biological concept of "royal blood" probably seems silly. At the same time, however, we know that there are distinguishing blood groups. For example, most of us are familiar with the ABO and Rh blood-typing systems. According to Lewontin (1997), there are roughly 35 blood group systems, with 15 serving at least somewhat effectively to distinguish different human populations. Royal blood, at least within families, may well be distinguishable in terms of blood groups, just as the blood of nonroyal families would. So in this trivial sense royal blood can be said to exist, but differently in different royal families. In this same trivial sense, there can be differences in distributions of blood groups across religious groups, people with different body shapes, or people with different skin colors.

How mixtures are labeled is a function of social status. In the United States, Blacks generally have lower social status than Whites, so supposed admixtures of blood determine degrees of "blackness." Possessing any blackness makes one Black to some degree. So one can be light Black, medium-skinned, or dark Black, but one is still Black. Even if individuals of mixed parentage inherited none of the physical features of blackness, they would still be classified as Black, although they might pass for White (Fish, 2002). In areas where Blacks are of higher social status, degrees of whiteness may all be seen as departures from true blackness.

The concept of race serves a social rather than a biological purpose. Different types of parentage have, at various times and places, given rise to racial labeling (e.g., "Aryan race," "German race," and "Jewish race"). In apartheid South Africa, the races were Bantu (Black African), colored (including people of perceived mixed descent), Indian/Asian, and White. In contemporary North American society, we mix together the Black and colored "races," somehow believing, as noted, that individuals who possess any degree of nonwhiteness should be grouped in the Black category. Hitler designated as a member of the Jewish race anyone who had supposed Jewish blood, which could date back to one's great-grandparents.

In parts of Brazil, the supposed races are different again (Fish, 2002). A loura has straight blond hair, blue or green eyes, light skin color, and a narrow nose and thin lips. A branca has light skin color, eyes and hair of any color, a nose that is not broad, and nonthick lips. In Brazil, Fish pointed out, a branca is White. In the United States, a branca individual from Brazil would more likely be classified as "Hispanic." Then there is a morena, who has brown or black hair that is wavy or curly but not tightly curly and has tan skin, a nose that is not narrow, and lips that are not thin. Morenas in the United States are classified as Black or Hispanic. There are a number of other Brazilian terms used to describe socially constructed racial categories, such as mulata and preta, and to the Brazilians these terms are every bit as real as the Black, White, and Asian categories are in the United States. They are real. But as in the United States, they are folk, not biological, taxonomies used to socially stratify people, often in the name of science. At best, the effects are innocuous. At worst, they become the bases of genocide.

People generally use skin color to distinguish races, but not always. During the genocide in Rwanda, the Hutus used other physical attributes, such as height, to distinguish Tutsis. Because there had been so much intermarriage between Hutus and Tutsis, the distinctions were generally weak, and many people were killed simply because they seemed closer to the imagined Tutsi prototype than the Hutu one, regardless of their origins. At the time this article was being written, massacres were going on in parts of Darfur, Sudan, motivated by similar socially constructed distinctions.

The history of the concept of race is inextricably intertwined with attempts by the winners to explain or justify why they perceive themselves to be winners. Consider, for example, the term Caucasian. It is an odd term, in some ways, because although it is used to refer to "Whites," in Russia people from the Caucuses are considered dark relative to many other Russians. Especially be- 
cause of difficulties in Chechnya and surrounding areas, these dark Caucasians today are viewed with suspicion and distrust in much of Russia. So the term that is accepted as "scientifically" identifying White people in the United States, often in preference to the term White to give more of a feeling of scientific classification, is used in a way that is largely opposite in contemporary Russia. Where did the term come from then? It was coined by Johann Friedrich Blumenbach (as cited in Gould, 1994), who chose the name because he believed that the Georgians, from the Mount Caucasus region, are the most beautiful race of men (his words). The term stuck. So people in English-speaking countries with white skin have the honor of having a name they imagine to be the formal label for their race, representing what one naturalist in 1795 believed was the most attractive "race" and what today largely is believed to have rather dark as opposed to white skin, according to Russian standards. Thus, the term is scientifically unsupportable and part of an old racist typology. The term is just as racist as Negroid and Mongoloid, terms the politically sensitive American will not use.

\section{Origins of the Concept of Race}

Whence emerged the concept of "race"? The concept of race as a classification scheme representing allegedly natural "types" distinguishable on the basis of clear visual attributes such as skin or eye color, hair texture, and certain facial and bodily features was initially introduced in the 17th century (Schiebinger, 1993). However, it took these ideas almost a century to attract the attention of scientific "authorities." According to Gould (1994), Linneaus (in 1758) first proposed four races: Americanus, Europaeus, Asiaticus, and Afer, or African. He also alluded to two other categories that did not prove as useful for social purposes as the other categories: wild boys (feral children) discovered in the forests and monsters, and hairy men with long tails who emerged from tales of travelers. Blumenbach (1775/1969), building on the work of Linneaus, first proposed a grouping of "races," namely, Caucasians, Mongolians, Ethiopians, and Malays. This early history was no more scientific than the later history was to be. That is, race started out as a not so subtle way of socially classifying and, ultimately, stratifying people hierarchically, as better or worse. For example, Linneaus viewed the White as sanguine and muscular and the Black as phlegmatic and relaxed.

Historically, the formation of the concepts of race and ethnicity was influenced by two main perspectives (Kevles, 1995). One perspective was formed in the context of the eugenics movement and was used to refer to presumed biological differences between socially defined populations (Huxley, 1951). The other perspective was formed in the context of physical anthropology and the social sciences and rejected the idea of the biological significance of racial classifications. It argued that race and ethnicity are primarily cultural and historical products of human history (Boas, 1942). Today, whereas some still defend the basis for the "gene-based evolutionary theory" of race (Rushton, 1995), the majority of cultural anthropologists are in agreement that race is a socially constructed, not an evolutionary determined or biologically supported, concept (Smedley, 1993). Of course, science does not find truth by majority rule. The problem with the concept of race is not that it is supported by only a minority of anthropologists, but that it has no scientific basis. Moreover, attempts to link intelligence, race, and genetics have also lacked an adequate scientific foundation.

\section{Intelligence, Race, and Genetics}

The explosion of genetic research within the past 10-15 years has brought the concept of race back to the surface, with some researchers arguing that new molecular data have given the concept of race new significance in the context of medicine and public health (Risch, Burchard, Ziv, \& Tang, 2002). One might think that, because the concept of race originated as a social proxy for the description of biological differences, at least the biologists studying race would agree on its definition. However, the reality is different. When variation in genetic markers or allelic variants is considered, opinions range widely. One view is that socially defined racial differentiation is most pronounced and even discontinuous when it is evaluated on the basis of continental residence (Risch et al., 2002). A second view is that there is continuity in genetic variation across socially defined races and that various races are not distinct; rather, there is a single lineage with a shared evolutionary fate (Templeton, 1999). According to this view, there is no biological value in the concept of race (Anon, 2001; Schwartz, 2001). However, in considering these positions, it is important to understand that, even within these extreme views, researchers agree that although human populations might differ dramatically in terms of proportions or frequencies of alternative forms of genes (i.e., allelic variants), they do not differ in the kinds of genes they possess (Snyder, 1951). In fact, both extreme views may have some merit (Tishkoff \& Kidd, 2004).

A key argument of this article is that race is every bit as real as royal blood. It exists in some trivial sense as a correlate of various biological groupings stemming from migration and breeding patterns, and no more. However, just as royal families are usually interconnected and difficult to partition off fully, defining the boundaries between races is impossible. As The American Heritage Dictionary of the English Language (2000) notes in regard to usage, "many cultural anthropologists now consider race to be more a social or mental construct than an objective biological fact" (p. 1441).

Although attempts have been made to establish genes for intelligence (Plomin, 1997; Plomin \& Spinath, 2004), none have been conclusively identified. A project aimed at identifying quantitative trait loci (QTL) contributing to genetic variation in intelligence (Plomin \& Spinath, 2004) has attempted to establish QTLs associated with intelligence. To date, however, whatever positive findings have emerged have either failed to replicate (Chorney et al., 1998; Hill, Chorney, \& Plomin, 2002; Hill et al., 1999; Plomin et al., 1995) or produced weak signals that have not yet been attempted to be replicated with independent sam- 
ples (Plomin et al., 2001). Of course, the future may bring conclusive identifications; we simply do not know yet.

As a result, virtually all attempts to study genes related to intelligence have been indirect, through studies of heritability. But heritability is itself a troubled concept. Are differences in intelligence between so-called races heritable? This question is difficult to answer in part because it is difficult even to say what can be concluded from the heritability statistic commonly used. Consider some facts about heritability (Sternberg \& Grigorenko, 1999).

\section{What Heritability Tells Us}

Heritability (also referred to as $h^{2}$ ) is the ratio of genetic variation to total variation in an attribute within a population. Thus, the coefficient of heritability tells us nothing about sources of between-population variation. Moreover, the coefficient of heritability does not tell us the proportion of a trait that is genetic in absolute terms, but rather the proportion of variation in a trait that is attributable to genetic variation within a specific population.

Trait variation in a population is referred to as phenotypic variation, whereas genetic variation in a population is referred to as genotypic variation. Thus, heritability is a ratio of variation in the phenotype being considered due to relevant genetic variation to phenotypic variation. Heritability has a complementary concept, that of environmentality. Environmentality is a ratio of variation in the phenotype being considered due to relevant environmental variation to phenotypic variation. Note that both heritability and environmentality apply to populations, not to individuals. There is no way of estimating heritability for an individual, nor is the concept meaningful for individuals. Consider a trait that has a heritability statistic of $70 \%$; it is nonsense to say that the development of the trait in an individual is $70 \%$ genetic.

Heritability is typically expressed on a 0 to 1 scale, with a value of 0 indicating no heritability whatsoever (i.e., no genetic variation in the trait) and a value of 1 indicating complete heritability (i.e., only genetic variation in the trait). Heritability and environmentality add to unity (assuming that the error variance related to measurement of the trait is blended into the environmental component). Heritability tells us the proportion of individual-difference variation in an attribute that appears to be attributable to genetic differences (variation) within a population. Thus, if IQ has a heritability of .50 within a certain population, then $50 \%$ of the variation in scores on the attribute within that population is due (in theory) to genetic influences. This statement is completely different from the statement that $50 \%$ of the attribute is inherited.

An important implication of these facts is that heritability is not tantamount to genetic influence. An attribute could be highly genetically influenced and have little or no heritability. The reason is that heritability depends on the existence of individual differences. If there are no individual differences, there is no heritability (because there is a zero in the denominator of the ratio of genetic to total trait variation in a given population).
For example, being born with two eyes is $100 \%$ under genetic control (except in the exceedingly rare case of severe dismorphologies, with which we do not deal here). Regardless of the environment into which a human being is born, he or she will have two eyes. But it is not meaningful to speak of the heritability of having two eyes, because there are no individual differences. Heritability is not 1 ; it is meaningless (because there is a zero in the denominator of the ratio) and cannot be sensibly calculated.

Consider a second complementary example, occupational status. It is associated with a statistically significant heritability coefficient (Plomin, DeFries, \& McClearn, 1990), but certainly it is not under direct genetic control. Clearly, there is no gene or set of genes for occupational status. How could it be heritable, then? Heredity can affect certain factors that in turn lead people to occupations of higher or lower status. Thus, if factors such as intelligence, personality, and interpersonal attractiveness are under some degree of genetic control, they may lead in turn to differences in occupational status. The effects of genes are at best indirect (Block, 1995). Other attributes, such as divorce, may run in families (i.e., show familiality), but again they are not under direct genetic control; in fact, the reason for such familiality may be that these attributes are culturally "inherited."

\section{Variation in Heritability Within a Given Population}

Heritability is not a fixed value for a given attribute. Although we may read about "the heritability of IQ" (e.g., Herrnstein \& Murray, 1994), there really is no single fixed value that represents any true, constant value for the heritability of IQ or anything else, as recognized by Herrnstein and Murray (1994) and most others in the field (e.g., Bouchard, 1997). Heritability depends on many factors, but the most important one is the range of environments. Because heritability represents a proportion of variation, its value will depend on the amount of variation. As Herrnstein (1973) pointed out, if there were no variation in environments, heritability would be perfect, because there would be no other source of variation. If there is wide variation in environments, however, heritability is likely to decrease.

When one speaks of heritability, one needs to remember that genes always operate within environment contexts. All genetic effects occur within a reaction range such that, inevitably, environment will have differential effects on the same genetic structure. The reaction range is the range of phenotypes (observable effects of genes) that a given genotype (latent structure of genes) for any particular attribute can produce, given the interaction of environment with that genotype. For example, genotype sets a reaction range for the possible heights a person can attain, but childhood nutrition, diseases, and many other factors affect the adult height realized. Moreover, if different genotypes react differently to environmental variation, heritability will show differences depending on the mean and variance in relevant environments (Lewontin, 1974). Thus, the statistic is not a fixed value. There are no pure genetic effects 
on behavior, as would be shown dramatically if a child were raised in a small closet with no stimulation. Genes express themselves through covariation and interaction with the environment, as discussed further later.

\section{Heritability and Modifiability}

Because the value of the heritability statistic is relevant only to existing circumstances, it does not and cannot address a trait's modifiability. A trait could have zero, moderate, or even total heritability and, in any of these conditions, be not at all, partially, or fully modifiable. The heritability statistic deals with correlations, whereas modifiability deals with mean effects. Correlations, however, are independent of score levels. For example, adding a constant to a set of scores will not affect the correlation of that set with another set of scores.

Consider height as an example of the limitation of the heritability statistic in addressing modifiability. Height is highly heritable, with a heritability level above .90 . Yet height also is highly modifiable, as shown by the fact that average heights have risen dramatically throughout the past several generations.

As an even more extreme example, consider phenylketonuria (PKU). PKU is a genetically determined, recessive condition that stems from a mutation in a single gene on chromosome 12 (with a heritability of 1), and yet its effects are highly modifiable. Feeding an infant with PKU a diet free of phenylalanine prevents the mental retardation that otherwise would become manifest. Note also that a type of mental retardation that once incorrectly was thought to be purely genetic is not. Rather, the mental retardation associated with PKU is the result of the interaction with an environment (a "normal" diet) in which the infant ingests phenylalanine. Take away the phenylalanine and you reduce the level of - or, in optimal cases, eliminate-mental retardation. Note that the genetic endowment does not change: The infant still has a mutant gene causing PKU. What changes is the manifestation of its associated symptoms in the environment. Similarly, we cannot change (at least on the basis of our knowledge today) the genetic structure underlying manifestations of intelligence (or any other trait); however, we can change those manifestations or expressions of genes in the environment. Thus, knowing the heritability of a trait does not tell us anything about its modifiability.

\section{Within-Population Effects Versus Between- Populations Effects}

One of the worst intellectual slips made by investigators of heredity and environment (or rather, most often, by interpreters of findings on heredity and environment) is to generalize the effects of within-population studies between populations. For example, some investigators have made attributions about effects of racial or ethnic group differences on the basis of behavior-genetic studies (Herrnstein \& Murray, 1994), even while admitting that such conclusions are sometimes flawed. All of the behavior-genetic designs used in the studies noted earlier can ascertain effects of genetic variation only within populations. For example, they may tell us something about the extent to which individual differences in the measured intelligence of people in a particular group are associated with genetic factors. They say nothing about sources of between-population differences in levels of measured intelligence.

Lewontin $(1972,1982)$ provided an illustration of the impossibility of making between-population claims from within-population data. Specifically, in a study involving the use of a set of protein markers (blood groups, serum proteins, and red blood cell enzymes) as indicators of genetic differences between populations, Lewontin estimated that roughly $85 \%$ of genetic variance occurs between any two individuals within any socially identified racial group; roughly $9 \%$ occurs among different populations within a socially identified race; and only the remaining $6 \%-7 \%$ occurs between socially identified races. Other researchers have arrived at the same conclusions using more powerful data sets obtained with more technologically advanced methodologies (Barbujani, Magagni, Minch, \& Cavalli-Sforza, 1997; K. K. Kidd et al., 2004; Rosenberg et al., 2002; Tishkoff \& Kidd, 2004) or through simulation analyses (Templeton, 1999).

Different populations-racial, ethnic, religious, or whatever - may encounter quite different environments, on average. Whatever the heritability of intelligence or other attributes within a given setting, no conclusions can be drawn about heritability as a source of differences across settings. The fact that IQs have increased so much over the years (Neisser, 1998) suggests that environments differ widely over time. They probably differ substantially as well for members of different groups at a given time.

Nisbett $(1995,1998)$ reviewed published studies investigating sources of differences in cognitive abilities between White and Black individuals. These studies, involving designs unlike the behavior-genetic studies described earlier, have directly sought to investigate genetic and environmental effects on intelligence. For example, one design has been to look at Black children adopted by White parents. Of seven published studies, six supported primarily environmental interpretations of group differences, and only one study did not; the results of the nonsupporting study (Scarr \& Weinberg, 1976, 1983) were equivocal. What the Scarr and Weinberg study did show is that IQs of adopted children are more similar to those of their biological mothers than to those of their adopted mothers. Less clear are the "racial" implications of their findings.

Moreover, there is much published evidence indicating that heritability estimates vary across populations. For example, estimates of the heritability of IQ in Russian twin studies conducted in the Soviet era tended to be higher than comparable estimates in the United States (Egorova, 1988; Grigorenko, 1990; Iskoldsky, 1988). This observation made sense: Environmental variation in Russia under the Soviet regime was constrained; consequently, heritability estimates were higher. Most of the IQ heritability studies up to today have been carried out in various countries of the developed world. Relatively little information exists regarding the heritability of IQ in the developing world, 
although some studies suggest that such heritability may be substantial, at least outside the Western countries that most often have been studied (Bratko, 1996; Lynn \& Hattori, 1990; Nathwar \& Puri, 1995; Pal, Shyam, \& Singh, 1997). Recently, Turkheimer, Haley, Waldron, D'Onofrio, and Gottesman (2003) showed that heritabilities differ radically across socioeconomic groups. Obviously, without even knowing much about estimates of the heritability of IQ in different populations, we cannot speculate at this point about differences across these populations.

In summary, heritability estimates do not explain the genetic regulation of behavior and do not provide accurate estimates of the strength of this regulation. Heritabilities are like snapshots of a dancer. They will not tell us either what the dance is about or what is coming next in the dance. The true genetic nature of humans is far from being defined. But what is absolutely clear is that genes do not act in a vacuum; they act in the environment, and their actions can be altered by the environment.

\section{Biological and Genetic Data as Related to the Concept of Race}

One would hope that, because the concept of race was originally, if falsely, conceived as a concept to signify the degree of biological differences between groups of people, the strongest support for the concept would originate from biological and genetic data. Does it? Here we review some examples of the relevant research.

First, it appears that the global distribution of genetic variation in humans is not easily sorted according to socalled races. As reviewed recently (Bamshad et al., 2003; Bamshad, Wooding, Salisbury, \& Stephens, 2004; K. K. Kidd et al., 2004; Tishkoff \& Kidd, 2004), scientists have studied diverse populations for many polymorphisms. These studies involve polymorphisms in the nuclear DNA, including variation in the nonrecombining $\mathrm{Y}$ chromosome (Underhill et al., 2000) and autosomal (i.e., located on chromosomes other than $\mathrm{Y}$ and $\mathrm{X}$ ) markers (e.g., K. K. Kidd et al., 2004) as well as polymorphisms in the mitochondrial DNA (Quintana-Murci et al., 1999). A clear picture has emerged of the distribution of genetic variation around the world, at least in broad strokes. These data overwhelmingly support the following model for recent human evolution and diversification of populations.

Modern Homo sapiens evolved in Africa about 200,000 years ago and then spread throughout the rest of the world and simultaneously diversified starting approximately 50,000 to 100,000 years ago. During that spreading out, modern humans supplanted now-archaic humanlike populations identifiable as having spread outside of Africa, such as Neanderthals.

The evidence is that effectively only one population left Africa and settled in southwestern Asia. That population was characterized by a large founder effect before it expanded into other regions. From that population, different pathways of expansion occurred: into Europe and separately across Asia. At some point in Asia, not yet clearly identifiable, additional expansions occurred, one expansion into northeastern Asia and then into the Americas along with a separate expansion into Melanesia and Australia. Associated with all of these expansions is accumulating random genetic drift at all polymorphic sites of the genome. Thus, allele frequencies generally show gradual changes as one moves around the world. Of course, recent migrations (over the past few thousand years) of established populations into already-occupied regions can result in some adjacent populations having very different allele frequencies, but that has been rare until historic times. Today in the United States, for example, we have populations from very different parts of that geographically continuous spectrum of allele frequencies. These distinct allele frequencies do not mean that different "races" exist, only that different parts of a continuum have been sampled. An analogy is the distinction among the colors blue, yellow, and red as samples from a continuous spectrum of light. These colors have meaning only because the spectral sensitivities of the photoreceptors in our eyes and the neurological circuits interpreting the signals interact with a label arbitrarily imposed on some narrow range of wavelengths from a continuous spectrum.

There is no question that populations, defined geographically, demonstrate dramatic variability in frequencies not only for the several million normal polymorphisms not associated with causing genetic disorders but also for many disease-related genetic alleles (variants). The genetic alleles (variants) can be readily seen in ALFRED, the ALlele FREquency Database (http://alfred.med.yale.med). The issue is not whether this variation is present or not; the issue is whether explaining this variation should occur at the levels of populations per se (e.g., Lapps, Chuvash, Nyanja, or Corsicans), continents (e.g., Europe or Africa), or alleged races. According to our review of the literature, variation that seems to be meaningful and transferable into helpful public health or educational policies is at the level of specific populations. Global socially constructed categories such as race do not appear to be useful proxies for genetic features.

Second, in considering evidence of a biological basis for racial classification, it is important to appreciate comparatively the amount of genetic variation observed within and among specific racial categories. In this context, let us turn for an illustration to the research on genetic bases of complex diseases. On the basis of rapidly accumulating evidence, a number of geneticists have argued that most common complex diseases, such as diabetes, hypertension, cancer, and so forth, appear to be at least partially governed by genetic mechanisms shared by most, if not all, populations around the world (Chakravarti, 1999; Daly, Rioux, Schaffner, Hudson, \& Lander, 2001). This statement has triggered a number of large-scale studies, including projects in Iceland and Estonia, where population-wide genome banks have been created in the hope of identifying specific alleles associated with common diseases within populations so that major pathways of genetic disorders can be discovered and later generalized to other populations (Frank, 2000; Gulcher \& Stefannson, 1998). The effectiveness of this approach is yet to be determined; however, there is encouragement for such an approach in the form of 
new evidence indicating that many uninterrupted or rarely interrupted chunks of DNA (referred as haplotypes) appear to be common across different populations socially classified as belonging to different races (Wilson et al., 2001).

To appreciate the significance of this finding, consider the example of population variability in mutations in the phenylalanine hydroxylase (PAH) gene, the gene whose disrupted protein results in the manifestation of PKU (as described earlier). It has been established that multiple mutations in this gene result in PKU. The mutations differ in terms of their specific location within the gene, and the frequencies of individual mutations vary across populations. However, each of these mutations appears to arise on one of a limited number of haplotypes and continues to be associated with that haplotype. Most common haplotypes are seen in all populations, and the greatest number of haplotypes are seen in African populations (J. R. Kidd et al., 2000).

Third, the essence of the race-intelligence-genetics discussion has been an assumption that if race is somehow a surrogate for unknown genetic mechanisms, then observed racial differences in intelligence and achievement can be explained by genetic differences. But can they be?

Although we have gained significant understanding of monogenetic (i.e., single-gene) conditions, there are still enormous blank spots in our understanding of complex human traits (i.e., traits controlled by many genes, often in combination with many environments) such as blood pressure, autism, reading disability, and intelligence. To illustrate, consider the observation that the majority of rare single-gene disorders (e.g., Tay Sachs, sickle-cell anemia, and thalassaemia) are caused by gene mutations that result in the production of changed and, therefore, often faulty proteins. In the literature, these deleterious mutations are typically referred to as "coding single nucleotide polymorphisms" (cSNPs). Consider two facts about cSNPs. First, they are rare; second, they are of recent origin, presumably dating to the post-African diaspora (Tishkoff \& Williams, 2002). Both assertions have implications for the discussion here.

First, the rarity of cSNPs implies that they are unlikely candidates for controlling quantitative traits such as blood pressure, bone density, and intelligence. The more likely candidates, as a result of their abundance, are so-called nontranscribed regulatory elements of the genome (i.e., a piece of DNA that does not contribute to the production of proteins or noncoding sequences). The amount of variation in these elements is remarkable. At present, the significance of this variation is unclear, because it has no obvious impact on the proteins. However, information from research involving organisms other than human ones is of interest here. For example, in Drosophila, these noncoding alleles have been closely associated with quantitative traits (Mackay, 2001).

Second, the timing of the origin of cSNPs is linked to the observation that their frequency varies among populations (Risch et al., 2002). The reasoning is simple. Because cSNPs arose after the differentiation of the populations, their distribution is a consequence of ethnic differentiation, not a reason for it. It appears that common noncoding variants, some of which are assumed to contribute to or even to underlie susceptibility to common diseases or variation in quantitative traits, are observed worldwide and can be referred to as "pan-ethnic" alleles (Cooper, 2003). In other words, to the best of our knowledge today, there are no explainable population differences in noncoding allele frequencies that can be meaningfully linked to variation in phenotypes. We simply do not see a clear pattern of ethnic differences in allele frequencies that can be associated with differences in specific phenotypes. Ethnic groups, of course, are socially defined. "Race" sounds like it is biologically defined. It is not. It, too, is socially defined.

\section{Social Versus Biological Definitions of Race}

When biological and behavioral markers of socially defined races are investigated, studies primarily or even exclusively rely on participants' self-reporting of socially defined racial, ethnic, and cultural groups. Many researchers use social labels such as Asian American, African American, Chinese, or Hispanic, implicitly ignoring the fact that these labels generalize across substantial amounts of cultural, linguistic, and biological diversity (Cooper et al., 2000). For example, "Hispanic" includes diverse populations from areas such as Cuba, Puerto Rico, the Dominican Republic, Guatemala, Costa Rica, Argentina, and, of course, Spain. The ancestry of individuals in these groups varies from entirely African, entirely Native American, and entirely European to any possible mixture of these three. Even ignoring the substantial variation within each of these large regions, there is no basis, except in the case of certain social cultural traits, for grouping these individuals. Even when a more specific populational reference such as Yoruba (i.e., a West African population of about 10 million people dispersed throughout different countries in the region) is made, this reference subsumes a great amount of intra-Yoruba variability (Reich et al., 2001).

Moreover, self-naming of social labels might change depending on the past and present social surroundings of surveyed participants. For example, during the Soviet era, many immigrating Soviet Jews referred to themselves as Jewish by ethnicity, but upon their arrival to Israel or the United States they referred to themselves as Russians (Gozman, 1997). In the United States, indeed, Judaism is viewed not as an ethnicity but as a religion. Similarly, individuals who met the classification of "colored" established by the apartheid government of South Africa would have probably identified themselves as Black in the United States (Braun, 2002). Thus, because most medical and psychological research on racial differences is based on self-defined racial or ethnic categories and there is substantial evidence questioning the accuracy of these self-classifications, the validity of racial and ethnic differences as commonly investigated is questionable.

People will probably always label themselves and others, regardless of what scientists find. The problem is not the use of social labeling per se, but rather the confusion of it with biological labeling. And it is especially problematic when scientists contribute to this confusion by 
using social labels in a way that suggests they are somehow biological.

The important message here is that the division lines between racial and ethnic groups "are highly fluid and that most genetic variation exists within all social groups-not between them" (Foster \& Sharp, 2002, p. 848). Recent studies based on hundreds of genetic polymorphisms confirm earlier studies, such as that of Lewontin $(1972,1982)$ cited earlier, and show that only $11 \%-23 \%$ of observed genetic variation is due to differences among populations and that this is mostly attributable to differences in allele frequencies, not all-or-nothing genetic differences (see review in Tishkoff \& Kidd, 2004). In fact, most common genetic variants exist in almost all populations. The overwhelming majority of the variation occurs among individuals with different genotypes within each population. One study revealed even less variation among populations (Rosenberg et al., 2002); highly polymorphic multiallelic markers were studied, however, and they may have been biased toward high heterozygosity (i.e., the two chromosomes of an individual having different alleles) in many different populations, thereby minimizing the betweenpopulation variation. Clearly, when common polymorphisms are studied, there is only a minority of the genetic variation that occurs among populations. Variants restricted to only a few populations in one part of the world are almost never common even in those populations.

Finally, let us regard whether and how the concept of race matters in such areas of life as public health and education. Here we consider examples from public health (U.S. National Center for Health Statistics, 2003). A review of age-adjusted death rates per 100,000 individuals for the year 2001 showed the following rates for White, Black, American Indian or Alaska Native, Asian or Pacific Islander, and Hispanic individuals: all causes, 836.5, 1,101.2, 686.7, 492.1, and 658.7, respectively; heart disease, 243.5, 316.9, 159.6, 137.6, and 192.2, respectively; malignant neoplasms, 193.9, 243.1, 131.0, 119.5, and 132.3, respectively; liver disease/cirrhosis, 9.6, 9.3, 22.6, 3.5, and 15.8, respectively; and diabetes mellitus, 23.0, 49.2, 40.4, 16.9, and 36.7 , respectively. Three points are important to mention here. First, there are clearly some group differences in these data. However, these differences are inconsistent; for example, the incidence of heart disease was highest among Blacks, whereas the incidence of liver disease was highest among American Indians or Alaska Natives. Second, all of these conditions are considered to be in part genetic disorders because of the overwhelming amount of data in the field attesting to the importance of genetic factors in the development and manifestation of these diseases. Third, all of these diseases are considered to be complex; therefore, the genetic mechanisms involved have not yet been decoded. As a result, we cannot argue that these observed differences in rates are genetic, because we do not know what the genetic mechanisms are (Cooper, 2003).

Similarly, there are group-average differences in scores on tests of academic abilities and achievement among children socially labeled as White, Black, Hispanic, and Asian. How large the differences are and what groups they favor depend on what, in particular, is tested. For example, Sternberg (in press) found that analytical tests of the kind traditionally used to measure so-called general abilities tend rather strongly to favor Americans of European and Asian origin, but tests of creative and practical thinking show quite different patterns. We also know that there is a substantial genetic influence contributing to individual differences in levels of academic achievement (Luo, Thompson, \& Detterman, 2003). Yet, we do not know a single gene that has been identified as contributing to either academic achievement or IQ. Thus, the statement that racial differences in IQ or academic achievement are of genetic origin is, when all is said and done, a leap of imagination. The literature on intelligence, race, and genetics constitutes, in large part, leaps of imagination to justify, post hoc, social stratifications. There is nothing wrong, in principle, with people expressing their views on social policy. But they need to recognize these views for what they are: social policy pronouncements, not science.

\section{Conclusion}

In conclusion, intelligence is, at this time, ill defined. Although many investigators study "IQ" or " $g$ " as an operational definition of intelligence, these operationalizations are at best incomplete, even according to those who accept the constructs as useful (e.g., Carroll, 1993). Research suggests that properties of intelligence beyond $g$ may be somewhat different from those of $g$ (e.g., Gardner, 1983; Sternberg et al., 2000, 2001). Race is a social construction, not a biological construct, and studies currently indicating alleged genetic bases of racial differences in intelligence fail to make their point even for these socialdefined groups. In general, we need to be careful, in psychological research, to distinguish our folk conceptions of constructs from the constructs themselves.

\section{REFERENCES}

American Heritage dictionary of the English language (4th ed.). (2000). Boston: Houghton Mifflin.

Anon, X. (2001). Genes, drugs and race. Nature Genetics, 29, 239-240.

Bamshad, M., Wooding, S., Salisbury, B. A., \& Stephens, J. C. (2004). Deconstructing the relationship between genetics and race. Nature Reviews Genetics, 5, 598-609.

Bamshad, M. J., Wooding, S., Watkins, W. S., Ostler, C. T., Batzer, M. A., \& Jorde, L. B. (2003). Human population genetic structure and inference of group membership. American Journal of Human Genetics, 72, 578-589.

Barbujani, G., Magagni, A., Minch, E., \& Cavalli-Sforza, L. L. (1997). An apportionment of human DNA diversity. Proceedings of the National Academy of Sciences, 94, 4516-4519.

Berry, J. W. (1974). Radical cultural relativism and the concept of intelligence. In J. W. Berry \& P. R. Dasen (Eds.), Culture and cognition: Readings in cross-cultural psychology (pp. 225-229). London: Methuen.

Block, N. (1995). How heritability misleads about race. Cognition, 56, 99-128.

Blumenbach, J. F. (1969). De generis humani varietate nativa [On the natural varieties of mankind]. New York: Bergman. (Original work published 1775)

Boas, F. (1942). Race, language, and culture. Chicago: University of Chicago Press. 
Boring, E. G. (1923, June 6). Intelligence as the tests test it. New Republic, pp. $35-37$.

Bouchard, T. J., Jr. (1997). IQ similarity in twins reared apart: Findings and responses to critics. In R. J. Sternberg \& E. L. Grigorenko (Eds.), Intelligence, heredity, and environment (pp. 126-160). New York: Cambridge University Press.

Brand, C. (1996). Doing something about g. Intelligence, 22, 311-326.

Bratko, D. (1996). Twin study of verbal and spatial abilities. Personality and Individual Differences, 21, 621-624.

Braun, L. (2002). Race, ethnicity, and health. Perspectives in Biology and Medicine, 45, 159-174.

Brownell, K. D., \& Horgen, K. B. (2003). Food fight: The inside story of the food industry, America's obesity crisis, and what we can do about it. New York: McGraw-Hill.

Carroll, J. B. (1993). Human cognitive abilities: A survey of factoranalytic studies. New York: Cambridge University Press.

Cattell, R. B. (1971). Abilities: Their structure, growth and action. Boston: Houghton Mifflin.

Cattell, R. B., \& Cattell, A. K. (1963). Test of g: Culture fair, Scale 3. Champaign, IL: Institute for Personality and Ability Testing.

Chakravarti, A. (1999). Population genetics: Making sense out of sequence. Nature Genetics, 21, 56-60.

Chorney, M. J., Chorney, K., Seese, N., Owen, M. J., Daniels, J., McGuffin, P., et al. (1998). A quantitative trait locus associated with cognitive ability in children. Psychological Science, 9, 159-166.

Cook, L. M. (2003). The rise and fall of the carbonaria form of the peppered moth. Quarterly Review of Biology, 78, 399-417.

Cooper, R. S. (2003). Race, genes, and health-New wine in old bottles? International Journal of Epidemiology, 32, 23-25.

Cooper, R. S., Guo, X., Rotimi, C. N., Luke, A., Ward, R., Adeyemo, A., \& Danilov, S. M. (2000). Heritability of angiotensin-converting enzyme and angiotensinogen: A comparison of US Blacks and Nigerians. Hypertension, 35, 1141-1147.

Daly, M. J., Rioux, J. D., Schaffner, S. F., Hudson, T. J., \& Lander, E. S. (2001). High-resolution haplotype structure in the human genome. Nature Genetics, 29, 229-232.

Egorova, M. S. (1988). Genotip i sreda v variativnosti kognitivnykh phunktsii [Genotype and environment in the variation of cognitive functions]. In I. V. Ravich-Shcherbo (Ed.), Rol' sredy I nasledstvennosti $v$ formirovanii individual'nosti cheloveka (pp. 181-235). Moscow: Pedagogika.

Fish, J. M. (2002). The myth of race. In J. M. Fish (Ed.), Race and intelligence: Separating science from myth (pp. 113-141). Mahwah, NJ: Erlbaum.

Flynn, J. R. (1984). The mean IQ of Americans: Massive gains 1932 to 1978. Psychological Bulletin, 95, 29-51.

Flynn, J. R. (1987). Massive IQ gains in 14 nations. Psychological Bulletin, 101, 171-191.

Foster, M. W., \& Sharp, R. R. (2002). Race, ethnicity, and genomics: Social classifications as proxies of biological heterogeneity. Genome Research, 12, 844-850.

Frank, L. (2000, October 6). Population genetics: Estonia prepares for national DNA database. Science, 290, 31.

Gardner, H. (1983). Frames of mind: The theory of multiple intelligences. New York: Basic Books.

Gardner, H. (1999a). Are there additional intelligences? The case for naturalist, spiritual, and existential intelligences. In J. Kane (Ed.), Education, information, and transformation (pp. 111-131). Upper Saddle River, NJ: Prentice Hall.

Gardner, H. (1999b). Intelligence reframed: Multiple intelligences for the 21st century. New York: Basic Books.

Gould, S. J. (1994, November). The geometer of race. Discover, pp. 65-69.

Gozman, L. I. (1997). The last empire: A divorce in the family of nations. In E. L. Grigorenko, P. Ruzgis, \& R. J. Sternberg (Eds.), Psychology in Russia: Past, present, and future (pp. 395-432). Commack, NY: Nova Science.

Grigorenko, E. L. (1990). Esperimental'nor issledovanie protsessa vydvizheniia I proverki gipotez [Experimental study of hypothesis-making in the structure of cognitive activity]. Unpublished doctoral dissertation, Research Institute of the Academy of Pedagogical Sciences, Union of the Soviet Socialist Republics.
Grigorenko, E. L., Geissler, P. W., Prince, R., Okatcha, F., Nokes, C., Kenny, D. A., et al. (2001). The organization of Luo conceptions of intelligence: A study of implicit theories in a Kenyan village. International Journal of Behavior Development, 25, 367-378.

Gulcher, J., \& Stefannson, K. (1998). Population genomics: Laying the groundwork for genetic disease modeling and targeting. Clinical Chemistry and Laboratory Medicine, 36, 523-527.

Gustafsson, J. E. (1994). Hierarchical models of intelligence and educational achievement. In A. Demetriou \& A. Efklides (Eds.), Intelligence, mind, and reasoning: Structure and development. Advances in psychology (pp. 45-73). Amsterdam: North-Holland/Elsevier Science.

Harding, R. M., Healy, E., Ray, A. J., Ellis, N. S., Flanagan, N., Todd, C., et al. (2000). Evidence for variable selective pressures at MC1R. American Journal of Human Genetics, 66, 1351-1361.

Herrnstein, R. J. (1973). IQ in the meritocracy. Boston: Atlantic Monthly Press.

Herrnstein, R. J., \& Murray, C. (1994). The bell curve. New York: Free Press.

Hill, L., Chorney, M. C., \& Plomin, R. (2002). A quantitative trait locus (not) associated with cognitive ability? Psychological Science, 13, 561-562.

Hill, L., Craig, I. W., Asherson, P., Ball, D., Eley, T., Ninomiya, T., et al. (1999). DNA pooling and dense marker maps: A systematic search for genes for cognitive ability. NeuroReport, 10, 843-848.

Horn, J. L. (1994). Theory of fluid and crystallized intelligence. In R. J. Sternberg (Ed.), The encyclopedia of human intelligence (Vol. 1, pp. 443-451). New York: Macmillan.

Huxley, J. (1951). Genetics, evolution, and human destiny. In J. L. Dunn (Ed.), Genetics in the twentieth century: Essays on the progress of genetics during its first 50 years (pp. 591-621). New York: Macmillan.

"Intelligence and its measurement": A symposium. (1921). Journal of Educational Psychology, 12, 123-147, 195-216, 271-275.

Iskoldsky, N. V. (1988). Vliianie sotsial'no-psikhologicheskikh factorov na individual'nye osobennosti bliznetsov $i$ ikh vnutriparnoe skhodstvo [The influence of social-psychological factors influencing twins' individual characteristics and their similarity on psychological traits]. Unpublished doctoral dissertation, Research Institute of the Academy of Pedagogical Sciences, Union of the Soviet Socialist Republics.

Jensen, A. R. (1998). The g factor: The science of mental ability. Westport, CT: Praeger/Greenwood.

Kevles, D. (1995). In the name of eugenics: Genetics and the uses of human heredity. Cambridge, MA: Harvard University Press.

Kidd, J. R., Pakstis, A. J., Zhao, H., Lu, R. B., Okonofua, F. E., Odunsi, A., et al. (2000). Haplotypes and linkage disequilibrium at the phenylalanine hydroxylase locus, $\mathrm{PAH}$, in a global representation of populations. American Journal of Human Genetics, 66, 1882-1899.

Kidd, K. K., Pakstis, A. J., Speed, W. C., \& Kidd, J. R. (2004). Understanding human DNA sequence variation. Journal of Heredity, 95, 406-420.

Lewontin, R. C. (1972). The apportionment of human diversity. Evolutionary Biology, 6, 381-398.

Lewontin, R. C. (1974). Annotation: The analysis of variance and the analysis of causes. American Journal of Human Genetics, 26, 400-411.

Lewontin, R. (1982). Human diversity. New York: Freeman.

Lewontin, R. C. (1997). The apportionment of human diversity. In E. N. Gates (Ed.), Critical race theory (pp. 7-24). New York: Garland.

Luo, D., Thompson, L. A., \& Detterman, D. K. (2003). Phenotypic and behavioral genetic covariation between elemental cognitive components and scholastic measures. Behavior Genetics, 33, 221-246.

Lynn, R., \& Hattori, K. (1990). The heritability of intelligence in Japan. Behavior Genetics, 20, 545-546.

Mackay, T. F. C. (2001). Quantitative trait loci in Drosophila. Nature Review Genetics, 2, 11-20.

Mackintosh, N. J. (1998). IQ and human intelligence. Oxford, England: Oxford University Press.

Marks, J. (2002). Folk heredity. In J. M. Fish (Ed.) Race and intelligence: Separating science from myth (pp. 95-112). Mahwah, NJ: Erlbaum.

Nathwar, S., \& Puri, P. (1995). A comparative study of MZ and DZ twins on Level I and Level II mental abilities and personality. Journal of the Indian Academy of Applied Psychology, 21, 87-92.

Neisser, U. (Ed.). (1998). The rising curve. Washington, DC: American Psychological Association. 
Nisbett, R. E. (1995). Race, IQ, and scientism. In S. Fraser (Ed.), The bell curve wars (pp. 36-57). New York: Basic Books.

Nisbett, R. E. (1998). Race, genetics, and IQ. In C. Jencks \& M. Phillips (Eds.), The Black-White test score gap (pp. 86-102). Washington, DC: Brookings Institution.

Nisbett, R. E., \& Cohen, D. (1996). Culture of honor. Boulder, CO: Westview.

O’Neil, D. (2004, September 13). Skin color adaptation. Retrieved August 20, 2004, from http://anthro.palomar.edu/adapt/adapt_4.htm

Pal, S., Shyam, R., \& Singh, R. (1997). Genetic analysis of general intelligence ' $\mathrm{g}$ ': A twin study. Personality and Individual Differences, 22, 779-780.

Plomin, R. (1997). Identifying genes for cognitive abilities and disabilities. In R. J. Sternberg \& E. L. Grigorenko (Eds.), Intelligence, heredity, and environment (pp. 89-104). New York: Cambridge University Press.

Plomin, R., DeFries, J. C., \& McClearn, G. (1990). Behavioral genetics: A primer. New York: Freeman.

Plomin, R., Hill, L., Craig, I., McGuffin, P., Purcell, S., Sham, P., et al. (2001). A genome-wide scan of 1842 DNA markers for allelic associations with general cognitive ability: A five-stage design using DNA pooling and extreme selected groups. Behavior Genetics, 31, 497-509.

Plomin, R., McClearn, G. E., Smith, D. L., Skuder, P., Vignetti, S., Chorney, M. J., et al. (1995). Allelic associations between 100 DNA markers and high versus low IQ. Intelligence, 21, 31-48.

Plomin, R., \& Spinath, F. M. (2004). Intelligence: Genetics, genes, and genomics. Journal of Personality and Social Psychology, 86, 112-129.

Quintana-Murci, L., Semino, O., Bandelt, H. J., Passarino, G., McElreavey, K., \& Santachiara-Benerecetti, A. S. (1999). Genetic evidence of an early exit of Homo sapiens from Africa through eastern Africa. Nature Genetics, 23, 437-441.

Reich, D. E., Cargill, M., Bolk, S., Ireland, J., Sameti, P. C., Richter, D. J., et al. (2001). Linkage disequilibrium in the human genome. Nature, 411, 199-204.

Risch, N., Burchard, E., Ziv, E., \& Tang, H. (2002). Categorization of humans in biomedical research: Genes, race and disease. Genome Biology, 3(7), 1-12.

Rosenberg, N. A., Pritchard, J. K., Weber, J. L., Cann, H. M., Kidd, K. K., Zhivotovsky, L. A., \& Feldman, M. W. (2002, December 20). Genetic structure of human populations. Science, 298, 2381-2385.

Rushton, J. P. (1995). Race, evolution, and man. Princeton, NJ: Princeton University Press.

Scarr, S., \& Weinberg, R. A. (1976). IQ test performance of Black children adopted by White families. American Psychologist, 31, 726-739.

Scarr, S., \& Weinberg, R. A. (1983). The Minnesota adoption studies: Genetic differences and malleability. Child Development, 54, 260-267.

Schiebinger, L. (1993). Nature's body. Boston: Beacon Press.

Schwartz, R. S. (2001). Racial profiling in medical research. New England Journal of Medicine, 344, 1392-1393.

Skorecki, K., Selig, S., Blazer, S., Bradman, R., Bradman, N., Waburton, P. J., et al. (1997). Y chromosomes of Jewish priests. Nature, 385, 32.

Smedley, A. (1993). Race in North America: Origin and evolution of a worldview. Boulder, CO: Westview Press.

Snyder, L. H. (1951). Old and new pathways in human genetics. In L. C. Dunn (Ed.), Genetics in the twentieth century: Essays on the progress of genetics during its first 50 years (pp. 369-392). New York: Macmillan.

Sternberg, R. J. (1985). Implicit theories of intelligence, creativity, and wisdom. Journal of Personality and Social Psychology, 49, 607-627.

Sternberg, R. J. (1997). Successful intelligence. New York: Plume.

Sternberg, R. J. (1998). Abilities are forms of developing expertise. Educational Researcher, 27(3), 11-20.

Sternberg, R. J. (1999). Intelligence as developing expertise. Contemporary Educational Psychology, 24, 359-375.

Sternberg, R. J. (2003). What is an expert student? Educational Researcher, 32(8), 5-9.

Sternberg, R. J. (2004a). Culture and intelligence. American Psychologist, 59, 325-338.
Sternberg, R. J. (Ed.). (2004b). International handbook of intelligence. New York: Cambridge University Press.

Sternberg, R. J. (2004c). Psychology (4th ed.). Belmont, CA: Wadsworth. Sternberg, R. J., Conway, B. E., Ketron, J. L., \& Bernstein, M. (1981). People's conceptions of intelligence. Journal of Personality and Social Psychology, 41, 37-55.

Sternberg, R. J., \& Detterman, D. K. (Eds.). (1986). What is intelligence? Norwood, NJ: Ablex.

Sternberg, R. J., Forsythe, G. B., Hedlund, J., Horvath, J., Snook, S., Williams, W. M., et al. (2000). Practical intelligence in everyday life. New York: Cambridge University Press.

Sternberg, R. J., \& Grigorenko, E. L. (1999). Myths in psychology and education regarding the gene environment debate. Teachers College Record, 100, 536-553.

Sternberg, R. J., \& Grigorenko, E. L. (2002a). Dynamic testing. New York: Cambridge University Press.

Sternberg, R. J., \& Grigorenko, E. L. (Eds.). (2002b). The general factor of intelligence: How general is it? Mahwah, NJ: Erlbaum.

Sternberg, R. J., \& Kaufman, J. C. (1998). Human abilities. Annual Review of Psychology, 49, 479-502.

Sternberg, R. J., Nokes, K., Geissler, P. W., Prince, R., Okatcha, F., Bundy, D. A., \& Grigorenko, E. L. (2001). The relationship between academic and practical intelligence: A case study in Kenya. Intelligence, 29, 401-418.

Sternberg, R. J., with the Rainbow Project Collaborators. (in press). Augmenting the SAT through assessments of analytical, practical, and creative skills. In W. Camara \& E. Kimmel (Eds.), New tools for admission to higher education. Mahwah, NJ: Erlbaum.

Stringer, C. B. (1990, December). The emergence of modern humans. Scientific American, pp. 98-104.

Templeton, A. R. (1999). Human races: A genetic and evolutionary perspective. American Anthropologist, 100, 632-650.

Templeton, A. R. (2002). The genetic and evolutionary significance of human races. In J. M. Fish (Ed.), Race and intelligence: Separating science from myth (pp. 31-56). Mahwah, NJ: Erlbaum.

Tishkoff, S. A., Dietzsch, E., Speed, W., Pakstis, A. J., Kidd, J. R., Cheung, K., et al. (1996, March 8). Global patterns of linkage disequilibrium at the CD4 locus and modern human origins. Science, 271, 1380-1387.

Tishkoff, S. A., \& Kidd, K. K. (2004). Implications of biogeography of human populations for 'race' and medicine. Nature Genetics, 36(11, Suppl.) pp. S21-S27.

Tishkoff, S. A., \& Williams, S. M. (2002). Genetic analysis of African populations: Human evolution and complex disease. Nature Review Genetics, 3, 611-621.

Turkheimer, E., Haley, A., Waldron, M., D’Onofrio, B., \& Gottesman, I. I. (2003). Socioeconomic status modifies heritability of IQ in young children. Psychological Science, 14, 623-628.

Underhill, P. A., Shen, P., Lin, A. A., Jin, L., Passarino, G., Yang, W. H., et al. (2000). Y chromosome sequence variation and the history of human populations. Nature Genetics, 26, 358-361.

U.S. National Center for Health Statistics. (2003). Age-adjusted death rates for selected causes of death, according to sex, race, and Hispanic origin: United States, selected years 1950-2001. Retrieved August 20, 2004, from www.cdc.gov/nchs/data/hus/tables/2003/03hus029.pdf

Vernon, P. E. (1971). The structure of human abilities. London: Methuen.

Walter, R. C., Buffler, R. T., Bruggemann, J. H., Guillaume, M. M., Berhe, S. M., Negassi, B., et al. (2000). Early human occupation of the Red Sea coast of Eritrea during the last interglacial. Nature, 405, 65-69.

Wilson, J. F., Weale, M. E., Smith, A. C., Gratrix, F., Fletcher, B., Thomas, M. G., et al. (2001). Population genetic structure of variable drug response. Nature Genetics, 29, 265-269.

Yang, S., \& Sternberg, R. J. (1997a). Conceptions of intelligence in ancient Chinese philosophy. Journal of Theoretical and Philosophical Psychology, 17, 101-119.

Yang, S., \& Sternberg, R. J. (1997b). Taiwanese Chinese people's conceptions of intelligence. Intelligence, 25, 21-36. 